\title{
Accuracy of self-reported height, weight and BMI in a multiethnic Asian population
}

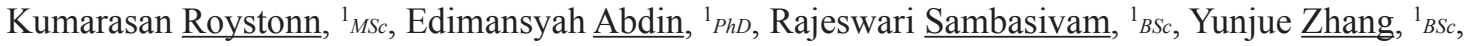
Sherilyn Chang, ${ }_{B S o c S c}$, Saleha $\underline{\text { Shafie, }},{ }_{B S c}$, Boon Yiang $\underline{\text { Chua }},{ }^{1} M S c$, Janhavi Ajit Vaingankar, ${ }^{1} M S c$, Siow Ann Chong, ${ }^{1}$ MMed, Mythily Subramaniam, ${ }^{1,2,3}$ PhD

\begin{abstract}
Introduction: The study assessed whether self-reported height, weight and derived body mass index (BMI) can provide an accurate measure of anthropometric data in a multiethnic adult population in Singapore.

Methods: Standardised anthropometric measurements were compared against the self-reported values from 5,132 adult residents in a cross-sectional, epidemiological survey. Discrepancies in self-reports from measurements were examined by comparing overall mean differences. Intraclass correlations, Cohen's kappa and Bland-Altman plots with limits of agreement, and sub-analysis by sex and ethnicity were also explored.

Results: Data were obtained from 5,132 respondents. The mean age of respondents was 43.9 years. Overall, the height was overestimated $(0.2 \mathrm{~cm})$, while there was an underestimation of weight $(0.8 \mathrm{~kg})$ and derived BMI $\left(0.4 \mathrm{~kg} / \mathrm{m}^{2}\right)$. Women had a larger discrepancy in height $(0.35 \mathrm{~cm}, 95 \%$ confidence interval [CI] 0.22 to 0.49$)$, weight $(-0.95 \mathrm{~kg}, 95 \%$ CI -1.11 to -0.79$)$ and BMI $\left(-0.49 \mathrm{~kg} / \mathrm{m}^{2}, 95 \%\right.$ CI -0.57 to -0.41$)$ compared with men. Height reporting bias was highest among Indians $(0.28 \mathrm{~cm}, 95 \%$ CI 0.12 to 0.44$)$ compared with Chinese and Malays, while weight $(-1.32 \mathrm{~kg}, 95 \%$ CI -1.53 to -1.11$)$ and derived BMI $\left(-0.57 \mathrm{~kg} / \mathrm{m}^{2}, 95 \%\right.$ CI -0.67 to -0.47$)$ showed higher degrees of underreporting among Malays compared with Chinese and Indians. Substantially high self-reported versus measured values were obtained for intraclass correlations $(0.96-0.99, P<0.001)$ and kappa $(0.74)$. For BMI categories, good to excellent kappa agreement was observed $(0.68-0.81, P<0.0001)$.

Conclusion: Self-reported anthropometric estimates can be used, particularly in large epidemiological studies. However, sufficient care is needed when evaluating data from Indians, Malays and women as there is likely an underestimation of obesity prevalence.
\end{abstract}

Ann Acad Med Singap 2021;50:306-14

Keywords: Body mass index, epidemiology, public health, self-report, validity

\section{INTRODUCTION}

Overweight and obesity continue to be one of the most critical public health issues worldwide. ${ }^{1,2}$ Body mass index (BMI) derived from height and weight has been directly linked to a number of debilitating diseases, including diabetes, heart disease and cancer, ${ }^{3}$ and has gained increased popularity as a measure of obesity. ${ }^{4,5}$ To date, BMI is the best available indicator used to assess overweight or obesity status for public health purposes, and accuracy of bodily dimensions are of crucial importance. ${ }^{6,7}$
Self-reported height and weight are widely used for BMI calculations, as obtaining clinical measurements for all individuals can be impractical and expensive, particularly in large-scale epidemiological surveys. ${ }^{7,8}$ Self-reports provide a non-invasive, inexpensive and practical means to obtain the anthropometric data rapidly. Previous studies have shown that self-reported height and weight may correlate well with measured values, even though some individuals may overestimate height and underestimate weight. ${ }^{9-12}$ Much less research has examined the accuracy of self-reported height and

\footnotetext{
${ }^{1}$ Research Division, Institute of Mental Health, Singapore

${ }^{2}$ Lee Kong Chian Medical School, Nanyang Technological University, Singapore

${ }^{3}$ Saw Swee Hock School of Public Health, National University of Singapore, Singapore

Correspondence: Mr Kumarasan Roystonn, Research Division, Institute of Mental Health, Buangkok Green Medical Park, 10 Buangkok View, Singapore 539747.

Email: k_roystonn@imh.com.sg
} 


\section{CLINICAL IMPACT}

\section{What is New}

- This study is one of the first to assess accuracy of self-reported anthropometric indicators in Singapore.

- Despite discrepancies among women and ethnic minorities, significant and substantial agreement was found for self-reports in Singapore.

\section{Clinical Implications}

- The study supports the use of self-reported height and weight data, particularly in large epidemiological studies.

- Caution is needed when reporting data from Indians, Malays and women as there is likely underestimation of obesity prevalence.

- This study guides efforts to improve calculation of disease risks when relying on self-reports.

weight when used to derive BMI categories. ${ }^{13,14}$ Yet, BMI outcomes are rather frequently used in healthrelated studies of various cohorts. ${ }^{15-18}$ Many of these studies have also found significant differences in BMI classification based on self-reported height and weight, compared with objective measurements. These differences can result in potential miscalculation of disease risks and could lead to inaccurate health decisions for the population being studied. ${ }^{14,18}$

Research suggests that the accuracy of self-reported anthropometric measures may vary significantly according to $\operatorname{sex}^{11}$ and race or ethnicity. ${ }^{19,20}$ Women more than men are found to underreport weight, while men more than women tend to overreport height. ${ }^{21}$ Some studies have shown that underestimating the overweight or obesity prevalence based on self-reported height and weight varies significantly among ethnic groups, independent of other sociodemographic characteristics. ${ }^{20,22}$ That is, minority ethnic groups were least likely to correctly classify themselves as overweight and obese. ${ }^{22}$ Research also suggests a tendency to present a socially desirable appearance in terms of anthropometric indicators, which may vary according to cultural or social expectations of particular ethnic groups. ${ }^{23}$

However, much of this research has been performed primarily on Western populations. The accuracy of self-reported anthropometric measurements in Asian contexts may, however, differ from Westerners because of body size and cultural differences (e.g. diet or weight perceptions)..$^{16,18}$ For instance, an international study comparing 22 countries reported that the trend towards misperception of overweight and attempts to lose weight were highest among those from Asian countries. ${ }^{18}$ Hence, findings on the validity of self-reported height and weight in Western populations may not necessarily be generalisable to Asian populations. In a review of 64 studies, Connor Gorber and colleagues ${ }^{8}$ found only 2 studies that had been conducted in an Asian population. ${ }^{12,16}$ However, these 2 studies were confined to specific subpopulations in Japan (i.e. mature civil servants, female office employees), and both studies suggested that self-reported height, weight and BMI were generally accurate and could be reliably used. Similar findings regarding the reliability of self-reported anthropometrics were reported in a more recent study conducted in Malaysia. ${ }^{17}$ The researchers stated that self-reported data were consistent with measurements, providing a reliable tool to monitor nutritional status in extensive health surveys, but were generalisable only to the student population. An updated systematic review of the literature ${ }^{24}$ revealed that Asian people were less likely to show bias in their self-reporting of anthropometric information than Western populations in other continents, including North America, Europe and Australia.

Despite these findings, there still remains a considerable research gap in the accuracy of self-reported height, weight and BMI compared with the measured values among the general adult population, particularly in Singapore. This study attempted to fill this knowledge gap using a nationally representative sample of adults in Singapore. Specifically, this study assessed the differences in sex and ethnicity on the degree of discrepancy between self-reported and measured height and weight in a multiethnic adult sample of residents living in Singapore.

\section{METHODS}

\section{Study population}

Data were derived from the Singapore Mental Health Study in 2016, designed to assess the state of mental health of the general population in Singapore. ${ }^{25}$ In brief, the sampling frame was based on a population database of all Singapore citizens and permanent residents, and selected subgroups (aged 65 and above, those of Malay and Indian ethnicity) were oversampled to ensure statistically reliable estimates. ${ }^{25}$

\section{Study procedure}

Participants received an invitation letter, followed by a home visit. Trained interviewers obtained written 
informed consent prior to conducting a face-to-face interview with those who agreed to participate in the study. Interviewers conducted all study procedures in the language preferred by participants (English, Chinese or Malay). Residents who were incapable of doing an interview owing to severe physical or mental conditions, language barriers, prolonged institutionalisation or hospitalisation, and those who were uncontactable because of incorrect address or not being in the country during the survey period, were excluded from the survey. Ethics approval was obtained from the National Healthcare Group, Domain Specific Review Board for the study.

\section{Measures}

\section{Questionnaire and self-report}

Participants first provided basic demographic information, including sex, age and ethnicity. Participants were asked to self-report weight and height to the nearest integer in the survey's initial section. At the end of the survey, their height and weight were measured by interviewers. Participants were provided an option to report in non-metric units. The weight in stones or pounds (32 cases) and height in feet or inches (639 cases) were converted to metric units of kilograms and centimetres with a standard algorithm that minimises potential biases in participants "calculating" height and weight in self-reports.

\section{Standard measuring procedure}

Prior to home visits, all interviewers were trained to obtain anthropometric measurements. Participants were first instructed to remove shoes, heavy outer garments and personal belongings from their pockets. For height measurements, participants stood with feet and back directly against a wall. A flat board (e.g. clipboard) was adjusted to rest on the top of the head at the highest point parallel to the floor, and a mark level with the participant's head was made on a self-adhesive note placed on the wall. A measuring tape was used to measure the perpendicular length from the floor to the mark on the note. Weight was measured with a standard, digital weighing scale that interviewers brought with them. Participants were asked to look straight ahead and step onto the machine after scale calibration was set to zero.

\section{BMI classification}

BMI was calculated using the formula of weight in kilograms divided by the square of height in metres $(\mathrm{kg} /$ $\mathrm{m}^{2}$ ). Although other classifications have been suggested and intermittently used in Asian populations, the World Health Organization (WHO) classification was used in this study for consistency and comparability with most existing international studies. The WHO international classification for BMI was underweight $\left(<18.5 \mathrm{~kg} / \mathrm{m}^{2}\right)$, healthy weight $\left(18.5-24.9 \mathrm{~kg} / \mathrm{m}^{2}\right)$, overweight $(25.0$ $\left.29.9 \mathrm{~kg} / \mathrm{m}^{2}\right)$ and obese $\left(\geq 30.0 \mathrm{~kg} / \mathrm{m}^{2}\right){ }^{6}$

\section{Statistical analyses}

All analyses incorporated sampling weights consistent with the sampling design of the 2016 Singapore Mental Health $\mathrm{Study}^{25}$ to take into account disproportionate sampling, adjustment for non-response, and poststratification for age and ethnic distributions between the study sample and resident population in 2014.

Outlying values of height and weight that were 3 standard deviations (SDs) away from the median were excluded. ${ }^{26}$ The median, like the mean, is a measure of central tendency, but the median absolute deviation is used for detecting outliers and is immune to sample size, unlike the mean. These properties have led to recommendations to use the median, ${ }^{28-30}$ which has been adopted in our study. In all, 22 cases were omitted. Nineteen cases with measurements of height $(53-94 \mathrm{~cm})$ and weight $(266 \mathrm{~kg})$ that did not seem plausible and 3 cases of self-reported height $(59-105 \mathrm{~cm})$ were removed. Additionally, participants with physical disabilities (wheelchair-bound or bedridden) and those who felt it was inconvenient or uncomfortable to have measurements taken by the interviewer were excluded. Some participants' measurements were also excluded as the equipment was not working during the interview. All cases were checked against interviewer-provided explanations prior to omission. As both self-reports and direct measurements were obtained in a single visit, the final analytic sample comprised 5,132 subjects with information of all 4 measures: self-reported and measured height and weight.

Descriptive analyses were performed to describe the demographic sample profile. Differences between selfreported and measured height, weight and BMI and corresponding standard deviations were obtained. The mean difference, intraclass correlation coefficient (ICC) and corresponding $95 \%$ confidence intervals (CI) for height, weight and BMI were tabulated and compared between respective self-reported and measured values. The ICC values ${ }^{30}$ range from 0 (no agreement) to 1 (perfect agreement). The Cohen's kappa $(\kappa)$ value determines the degree of agreement between BMI classification derived from self-reported values and direct measurements. ${ }^{31,32}$ The level of agreement is indicated by $\kappa<0$ (none or poor); $0 \leq \kappa \leq 0.20$ (slight); $0.21 \leq \kappa \leq 0.40 \quad$ (fair); $0.41 \leq \kappa \leq 0.60 \quad$ (moderate); $0.61 \leq \kappa \leq 0.80$ (substantial); and $0.81 \leq \kappa \leq 1.0$ (excellent 
or perfect). ICC for the pooled sample was calculated to assess the overall reliability and consistency of self-reports as a proxy for corresponding body measurements. The Bland-Altman plot is a robust statistical technique that provides a visual representation of the respective extent of underreporting and overreporting of height, weight and BMI when compared with measured values. ${ }^{33,34}$ Differences between the reported and measured values were plotted against the means of the reported and measured values, with a linear line representing the mean difference and $95 \%$ limits of agreement (LoA) calculated as mean difference \pm 1.96 (standard deviation of the difference). ${ }^{33}$ Agreement was regarded as "good" if the difference between the paired anthropometric unit was approximately equal to $1 \mathrm{SD}$ of the mean of the measured value, "fair" when the width was 2 SDs, and "poor" if the width was 3 SDs. ${ }^{35}$

\section{RESULTS}

\section{Sociodemographic characteristics of the sample}

In the study sample of $5,132,77.1 \%$ (weighted $n=1,595$ ) were Chinese, $8.6 \%$ (weighted $n=1,590$ ) were Indian and $11.1 \%$ (weighted $n=1,495$ ) were Malay. The mean (SD) age of participants was 43.9 (15.9) years, and $50.4 \%$ (weighted $n=2,667$ ) of the participants were men.

\section{Weighted mean differences between self-reported and measured values}

Table 1 presents the mean differences and corresponding $95 \%$ CI by sex and ethnicity. The discrepancy in height overestimation was larger in women $(0.35 \mathrm{~cm}, 95 \%$ CI 0.22 to 0.49$)$ than in men $(0.02 \mathrm{~cm} ; 95 \%$ CI -0.12 to $0.16)$. Women underreported their weights $(-0.95 \mathrm{~kg}$, $95 \%$ CI -1.11 to -0.79$)$ more than men $(-0.63 \mathrm{~kg} ; 95 \%$ CI -0.80 to -0.47$)$. Similarly, BMI among women was underestimated $\left(-0.49 \mathrm{~kg} / \mathrm{m}^{2}, 95 \% \mathrm{CI}-0.57\right.$ to -0.41$)$ more than the BMI for men $\left(-0.21 \mathrm{~kg} / \mathrm{m}^{2}, 95 \%\right.$ CI -0.28 to -0.14). Table 1 also shows that among the major ethnic groups, Indians had the largest discrepancy between their self-reported and measured heights $(0.28 \mathrm{~cm}, 95 \%$ CI 0.12 to 0.44$)$. Malays underreported the most for weight $(-1.32 \mathrm{~kg}, 95 \% \mathrm{CI}-1.53$ to -1.11$)$ and BMI $\left(-0.57 \mathrm{~kg} / \mathrm{m}^{2}, 95 \%\right.$ CI -0.67 to -0.47$)$, compared with the Chinese and Indians. Overall, there was a statistically significant overreporting of height by $0.2 \mathrm{~cm}(P<0.0001)$ and an underreporting of weight by over $0.7 \mathrm{~kg}(P<0.0001)$.

\section{Intraclass correlations and kappa for height, weight and BMI classification}

Table 2 presents the ICCs for self-reported and measured height, weight and BMI by sex and ethnicity. Although there was a notable discrepancy for self-reports compared with measured values at the individual level, in general the independent ICC for height, weight and BMI between corresponding self-reports and measurements were extremely high at 0.97 for height, 0.98 for weight, and 0.96 for BMI $(P<0.0001)$. Correspondingly, ICC was high in the sex and ethnic subgroup analysis as well. The ICCs for self-reported and measured values thus indicate an excellent degree of reliability. ${ }^{36}$

Overall, $82.9 \%$ of the participants had correctly classified their BMI status (underweight, healthy weight, overweight and obese) based on self-reported height and weight compared with measured data. Overweight and obese classification in self-reports were respectively underestimated by $1 \%$ and $2.5 \%$, while $3.1 \%$ and $0.4 \%$ respectively overestimated the healthy weight and underweight classification. Kappa value was substantially high for the whole sample $(\kappa=0.73)$ and substantially high to excellent for BMI categories of underweight $(\kappa=0.74)$, healthy weight $(\kappa=0.77)$, overweight $(\kappa=0.68)$ and obese $(\kappa=0.81)$ at $P<0.0001$ (Table 3). Table 3 also shows that women underreported by $0.4 \%$ and $3.9 \%$ for overweight and obese BMI status, respectively, while men underreported by $1.4 \%$ and $1.2 \%$ for these respective BMI categories. Among the Chinese, Malay and Indian ethnic groups, overweight and obese BMI categories were generally underreported. Specifically, $0.9 \%$ of the Chinese, $3.1 \%$ of the Malays and $3.5 \%$ of the Indians were found to have underreported their true obesity status when compared to BMI derived from measurements.

\section{Bland-Altman plots of the differences for height, weight and BMI classification}

Bland-Altman plots (limits of agreement [LoA]) were calculated to be $0.17 \pm 5.07$ for height (Fig. 1), $-0.72 \pm 5.99$ for weight (Fig. 2) and $-0.33 \pm 2.78$ for BMI (Fig. 3). The 95\% lower and upper limits were, respectively, -4.91 and 5.25 for height; -6.72 and 5.28 for weight; and -3.11 and 2.45 for BMI. The LoA for height and weight was smaller than $1 \mathrm{SD}$ of their respective measured values for height (standard deviation $9.1 \mathrm{~cm}$ ), and weight (standard deviation $13.4 \mathrm{~kg}$ ), showing good agreement overall in the use of self-reported assessments for height and weight compared with direct measurements.

\section{DISCUSSION}

This study was one of the first to report the accuracy of self-reported height and weight compared with objective measurements in a multiethnic Asian adult population. It was also one of the first to compare these differences 
Table 1. Mean of self-reported and measured height, weight and body mass index (BMI), discrepancy, and correlations by sex and ethnicity

\begin{tabular}{|c|c|c|c|c|c|}
\hline & & Mean of self-reported (SD) & Mean of measured (SD) & $\begin{array}{l}\text { Discrepancy between self-reported } \\
\text { and measured }(95 \% \mathrm{CI})\end{array}$ & $\begin{array}{c}\text { Correlation } \\
P \text { value }\end{array}$ \\
\hline \multirow[t]{8}{*}{ Height (cm) } & Sex & & & & \\
\hline & Female & $158.32(6.1)$ & $157.96(6.2)$ & $0.35(0.22$ to 0.49$)$ & $<0.0001$ \\
\hline & Male & $170.43(7.2)$ & $170.41(7.1)$ & $0.02(-0.12$ to 0.16$)$ & $<0.0001$ \\
\hline & Ethnicity & & & & \\
\hline & Chinese & $164.36(8.8)$ & $164.20(9.0)$ & $0.16(0.03$ to 0.28$)$ & $<0.0001$ \\
\hline & Malay & $163.56(9.0)$ & $163.34(9.1)$ & $0.22(0.06$ to 0.38$)$ & $<0.0001$ \\
\hline & Indian & $165.65(9.9)$ & $165.37(9.9)$ & $0.28(0.12$ to 0.44$)$ & $<0.0001$ \\
\hline & Overall & $164.41(9.0)$ & $164.24(9.1)$ & $0.17(0.08$ to 0.26$)$ & $<0.0001$ \\
\hline \multirow[t]{8}{*}{ Weight (kg) } & Sex & & & & \\
\hline & Female & $58.99(12.0)$ & $59.94(12.7)$ & $-0.95(-1.11$ to -0.79$)$ & $<0.0001$ \\
\hline & Male & $72.06(13.9)$ & $72.70(14.4)$ & $-0.63(-0.80$ to -0.47$)$ & $<0.0001$ \\
\hline & Ethnicity & & & & \\
\hline & Chinese & $64.01(13.6)$ & 64.67 (13.9) & $-0.65(-0.80$ to -0.50$)$ & $<0.0001$ \\
\hline & Malay & $71.14(17.2)$ & $72.46(17.7)$ & $-1.32(-1.53$ to -1.11$)$ & $<0.0001$ \\
\hline & Indian & $71.05(15.5)$ & $72.25(16.3)$ & $-1.20(-1.40$ to -1.00$)$ & $<0.0001$ \\
\hline & Overall & $64.75(13.2)$ & $65.4(13.4)$ & $-0.72(-0.83$ to -0.61$)$ & $<0.0001$ \\
\hline \multirow[t]{8}{*}{ BMI $\left(\mathbf{k g} / \mathbf{m}^{2}\right)$} & Sex & & & & \\
\hline & Female & $23.54(4.6)$ & $24.03(4.9)$ & $-0.49(-0.57$ to -0.41$)$ & $<0.0001$ \\
\hline & Male & $24.77(4.3)$ & $24.98(4.4)$ & $-0.21(-0.28$ to -0.14$)$ & $<0.0001$ \\
\hline & Ethnicity & & & & \\
\hline & Chinese & $23.59(4.0)$ & $23.88(4.2)$ & $-0.29(-0.36$ to -0.22$)$ & $<0.0001$ \\
\hline & Malay & $26.53(5.8)$ & $27.11(6.0)$ & $-0.57(-0.67$ to -0.47$)$ & $<0.0001$ \\
\hline & Indian & $25.85(5.0)$ & $26.37(5.3)$ & $-0.52(-0.61$ to -0.43$)$ & $<0.0001$ \\
\hline & Overall & $23.92(4.0)$ & $24.25(4.2)$ & $-0.33(-0.38$ to -0.28$)$ & $<0.0001$ \\
\hline
\end{tabular}

CI: confidence interval; SD: standard deviation

a Significance at $P<0.05$

by sex and ethnic groups in Singapore. Previous research has thus far focused primarily on Western populations or evaluated discrepancies with anthropometric selfreported data in specific subpopulations, and typically with ethnic groups combined. Comparable with studies of general population samples, ${ }^{10,11,37,38}$ our results showed a general underreporting of weight (by $0.7 \mathrm{~kg}$ ) and an overreporting of height (by $0.2 \mathrm{~cm}$ ). Also, the selfreported weight and height had discrepancies of less than $2 \mathrm{~kg}$ and less than $2 \mathrm{~cm}$, respectively, which were well within margins of acceptable error and thus considered a reliable estimate of clinical measurements. ${ }^{39}$
This study provides cross-cultural evidence and serves to ensure researchers can use the self-reported data with confidence.

One interesting finding was that our results showed greater reporting biases among women for both height and weight, unlike other research that found men overreporting height and women underreporting weight. ${ }^{21}$ One reason could be that most men in the sample (mean age $44.2 \pm 16.4$ years) were involved in military national service, which is a requirement until the age of 40 or 50 years, and consists of regular health assessments. Thus the men may have reference to more 
Table 2. Intraclass correlation (ICC) for self-reported and measured height, weight and body mass index (BMI) by sex and ethnicity ${ }^{\mathrm{a}}$

\begin{tabular}{|c|c|c|c|}
\hline & Single-measure ICC (95\% CI) & Average-measure ICC (95\% CI) & $P$ value $^{\mathrm{b}}$ \\
\hline \multicolumn{4}{|l|}{ Height } \\
\hline Female & 0.85 (0.84 to 0.86$)$ & 0.92 (0.91 to 0.92$)$ & $<0.0001$ \\
\hline Male & 0.89 ( 0.88 to 0.89$)$ & $0.94(0.94$ to 0.94$)$ & $<0.0001$ \\
\hline Chinese & $0.95(0.95$ to 0.96$)$ & $0.98(0.98$ to 0.98$)$ & $<0.0001$ \\
\hline Malay & 0.89 ( 0.88 to 0.90$)$ & $0.94(0.94$ to 0.95$)$ & $<0.0001$ \\
\hline Indian & $0.93(0.92$ to 0.94$)$ & $0.96(0.96$ to 0.97$)$ & $<0.0001$ \\
\hline Overall & $0.94(0.93$ to 0.94$)$ & $0.97(0.96$ to 0.97$)$ & $<0.0001$ \\
\hline \multicolumn{4}{|l|}{ Weight } \\
\hline Female & 0.97 (0.97 to 0.97$)$ & 0.98 (0.98 to 0.99$)$ & $<0.0001$ \\
\hline Chinese & $0.98(0.97$ to 0.98$)$ & $0.99(0.99$ to 0.99$)$ & $<0.0001$ \\
\hline Malay & 0.97 (0.97 to 0.97$)$ & 0.98 (0.98 to 0.99$)$ & $<0.0001$ \\
\hline Indian & 0.97 (0.97 to 0.97$)$ & 0.99 (0.98 to 0.99$)$ & $<0.0001$ \\
\hline Overall & 0.97 (0.97 to 0.97$)$ & $0.98(0.98$ to 0.98$)$ & $<0.0001$ \\
\hline \multicolumn{4}{|l|}{ BMI } \\
\hline Female & $0.94(0.94$ to 0.95$)$ & 0.97 (0.97 to 0.97$)$ & $<0.0001$ \\
\hline Male & $0.93(0.93$ to 0.94$)$ & 0.97 (0.96 to 0.97$)$ & $<0.0001$ \\
\hline Chinese & $0.94(0.93$ to 0.94$)$ & 0.97 (0.97 to 0.97$)$ & $<0.0001$ \\
\hline Malay & $0.93(0.92$ to 0.94$)$ & $0.96(0.96$ to 0.97$)$ & $<0.0001$ \\
\hline Overall & $0.93(0.92$ to 0.93$)$ & $0.96(0.96$ to 0.96$)$ & $<0.0001$ \\
\hline
\end{tabular}

BMI: body mass index CI: confidence interval

a ICCs estimate correlations between individual measurements and between average measurements made on the same anthropometric dimension. ICCs are based on 2-way mixed effects (random effects: self-report; fixed effects: measured values, consistency of agreement).

b Significance at $P<0.05$

accurate physical measurements in this sample. Still, our findings were similar to what has been reported elsewhere in the literature. ${ }^{10,11,37}$ For example, in the European Prospective Investigation into Cancer and Nutrition (EPIC)-Oxford study, ${ }^{11}$ British men and women described themselves as taller and weighing less, and women demonstrated a larger degree of biases in their reports.

Another interesting finding was that there were substantial ethnic differences in the self-reported discrepancies for height, weight and BMI classification. Indians and Malays presented greater biases in selfreporting height and weight, which led to greater misreporting of their true overweight or obesity status compared with the Chinese. In most studies and ours, the prevalence of obesity was significantly underestimated with self-reported data. ${ }^{14,24}$ However, the overall degree of misreporting for obesity prevalence in this study $(2.5 \%)$ was a little higher than what was previously found in other Asian samples. ${ }^{12}$ For example, a study in Japan reported that only $1.3 \%$ of civil servants had misclassified their overweight or obesity status $\left(\mathrm{BMI} \geq 25.0 \mathrm{~kg} / \mathrm{m}^{2}\right)$ compared with BMI derived from available measured data. Nevertheless, the researchers acknowledged that the high degree of correctness in self-reports was rather unique and not likely reproducible elsewhere. They further attributed this to a culture of attending regular health assessments at work, and the sample comprised employees from a single workplace. 


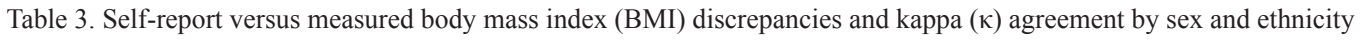

\begin{tabular}{|c|c|c|c|c|c|}
\hline BMI classification & Underweight & Healthy weight & Overweight & Obese & $P$ value \\
\hline \multicolumn{6}{|l|}{ Female } \\
\hline Measurement-based n (\%) & $154(6.1)$ & $1,179(46.3)$ & $710(27.9)$ & $504(19.8)$ & \\
\hline Report-based n (\%) & $176(6.9)$ & $1,267(49.7)$ & $700(27.5)$ & $404(15.9)$ & \\
\hline$\kappa$ & 0.75 & 0.78 & 0.67 & 0.80 & $<0.0001$ \\
\hline \multicolumn{6}{|l|}{ Male } \\
\hline Measurement-based n (\%) & $111(4.1)$ & $1,214(44.4)$ & $984(36.0)$ & $423(15.5)$ & \\
\hline Report-based n (\%) & $111(4.1)$ & $1,285(47.0)$ & $945(34.6)$ & $391(14.3)$ & \\
\hline$\kappa$ & 0.72 & 0.75 & 0.69 & 0.82 & $<0.0001$ \\
\hline \multicolumn{6}{|l|}{ Chinese } \\
\hline Measurement-based n (\%) & $110(6.9)$ & $957(59.6)$ & $420(26.2)$ & $119(7.4)$ & \\
\hline Report-based n (\%) & $118(7.4)$ & $984(61.3)$ & $400(24.9)$ & $104(6.5)$ & \\
\hline$\kappa$ & 0.79 & 0.77 & 0.73 & 0.80 & $<0.0001$ \\
\hline \multicolumn{6}{|l|}{ Malay } \\
\hline Measurement-based n (\%) & $74(4.7)$ & $521(33.3)$ & $542(34.6)$ & $429(27.4)$ & \\
\hline Report-based n (\%) & $76(4.9)$ & $599(38.3)$ & $511(32.6)$ & $380(24.3)$ & \\
\hline$\kappa$ & 0.68 & 0.73 & 0.64 & 0.82 & $<0.0001$ \\
\hline \multicolumn{6}{|l|}{ Indian } \\
\hline Measurement-based n (\%) & $63(3.8)$ & $670(40.7)$ & $583(35.4)$ & $329(20.0)$ & \\
\hline Report-based n (\%) & $72(4.4)$ & $704(42.8)$ & $598(36.4)$ & $271(16.5)$ & \\
\hline$\kappa$ & 0.75 & 0.77 & 0.67 & 0.78 & $<0.0001$ \\
\hline \multicolumn{6}{|l|}{ Overall } \\
\hline Measurement-based n (\%) & $265(5.2)$ & $2393(46.6)$ & $1692(33.0)$ & $782(15.2)$ & \\
\hline Report-based n (\%) & $287(5.6)$ & $2551(49.7)$ & $1643(32.0)$ & $651(12.7)$ & \\
\hline$\kappa$ & 0.74 & 0.76 & 0.68 & 0.78 & $<0.0001$ \\
\hline
\end{tabular}

In terms of accuracy of self-reported anthropometry in the local context, concerns would be greatest for health studies that rely on self-reports for women and certain ethnic groups. However, our results clearly supported that self-reports showed substantial agreement with objective measurements even in these subgroups. Despite the slight discrepancies identified with selfreported data at the individual level, our study showed that measured and reported height and weight were highly correlated. Our results corresponded with those from other studies, revealing high correlations $(>0.9)$ between self-reported and measured weight, height and BMI, respectively. ${ }^{8,10-12}$

The study findings should be considered with several limitations. First, there may be a sampling bias in excluding non-responders and those with missing self-reported or measured data. Yet, it is important to remove the outliers in order to reduce biases due to gross measurement errors in the sample. Nevertheless, this was the first study to explore the validity of anthropometric data in the general adult population at the national level in Singapore. The findings of this study replicate and extend valuable cross-cultural knowledge on the accuracy of self-reported height and weight. Second, we should interpret kappa statistics with caution. ${ }^{40}$ Third, participants may have known that they would be measured when they consented to the study, which might have reduced overall tendencies for misreporting. Additionally, the study did not collect information about participants' last visit to health professionals (e.g. health screening), which could influence the reporting accuracy. One can premise that 


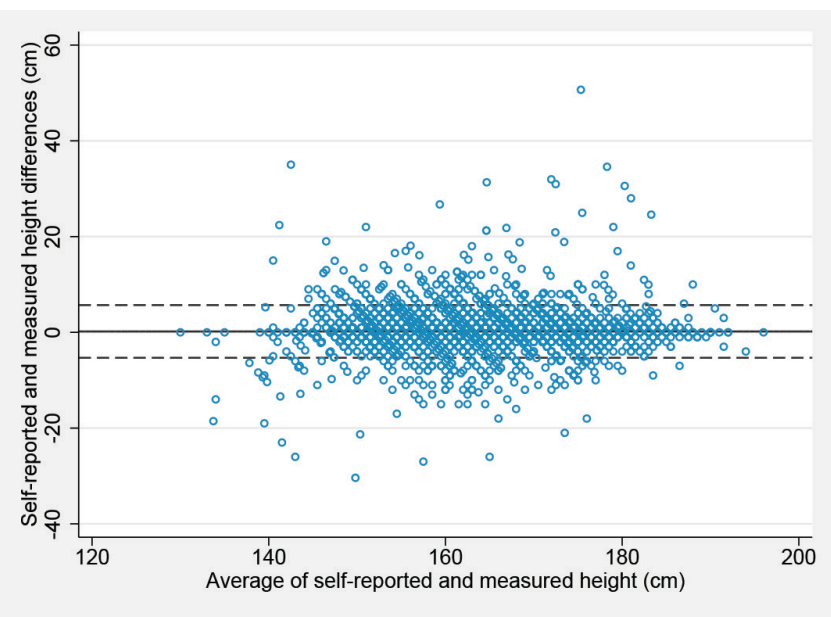

Fig. 1. Bland-Altman plot of the difference against the average of the reported and measured height. Broken lines represent $95 \%$ limits of agreement, \pm 1.96 standard deviation from the mean difference (solid line).

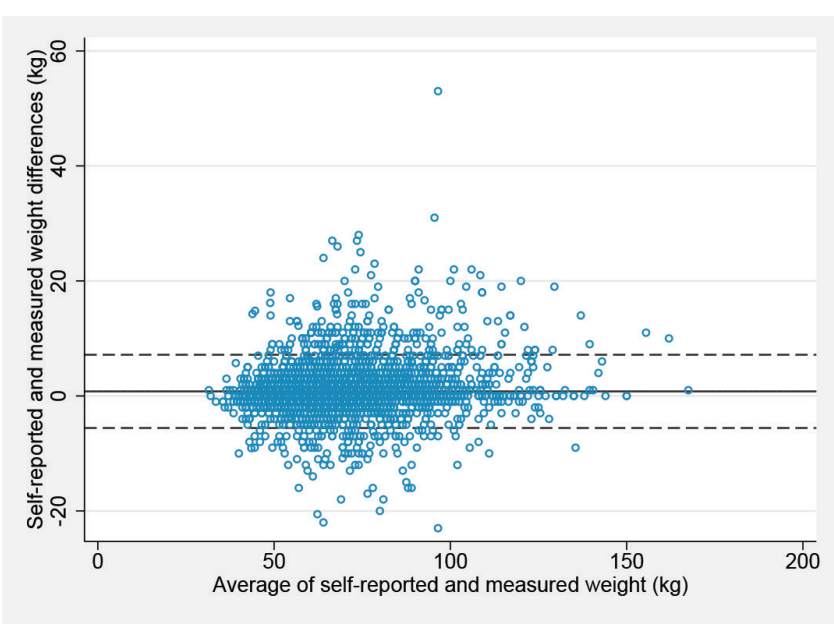

Fig. 2. Bland-Altman plot of the difference against the average of the reported and measured weight. Broken lines represent $95 \%$ limits of agreement, \pm 1.96 standard deviation from the mean difference (solid line).

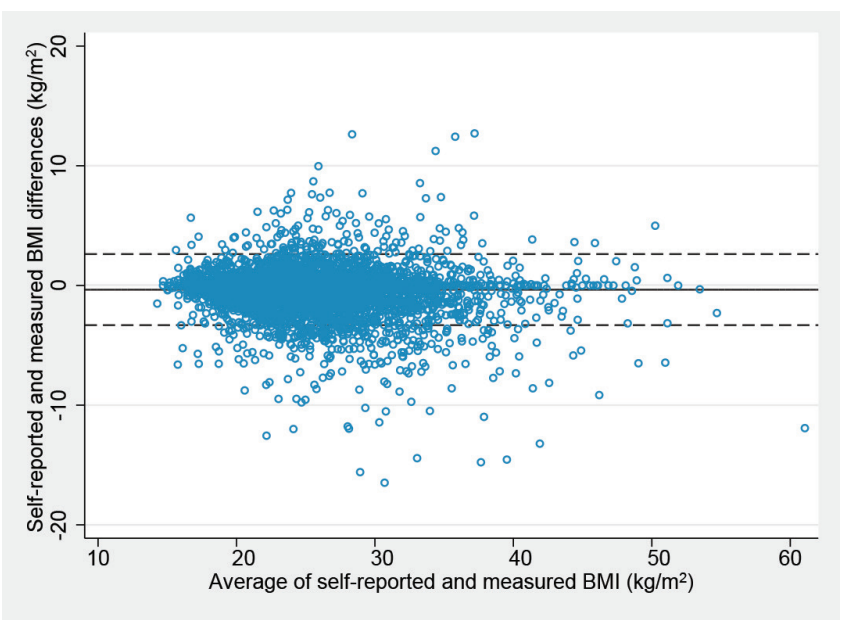

Fig. 3. Bland-Altman plot of the difference against the average of the reported and measured BMI. Broken lines represent $95 \%$ limits of agreement, $\pm 1.96 \mathrm{SD}$ from the mean difference (solid line). those who attended recent health examinations were more likely to be cognizant of their height and weight. Hence, our findings may have been susceptible to experimental influences in addition to potential social desirability bias. Despite these possible concerns, our results indicated substantially high agreement between self-reported and measured height, weight and BMI classification at the population level.

\section{CONCLUSION}

Public health studies must evaluate whether the potential for biases in anthropometric self-reports are present to an extent that suggests that it may be unsuitable for their specific clinical or research purpose, especially when probable miscalculations could lead to erroneous health conclusions for the population. ${ }^{14,18}$ Future research needs to evaluate potential factors that contribute to discrepancies in self-reported height and weight and derive a useful and convenient formula to correct for such self-reporting biases in the local population., ${ }^{9}, 21,35,39$ Up-to-date knowledge about these potential biases will be crucial for planning study designs and drawing conclusions with self-reported anthropometric data in local epidemiological studies.

To conclude, this study shows that while direct measurements are the optimal method, self-reported data on height and weight could be an accurate alternative, particularly in large epidemiological studies. Researchers should bear in mind that individuals, particularly women and those of Indian and Malay ethnicity, tend to overestimate height and underestimate weight, which translates into an underestimation of BMI. Hence, self-reported data may need to be interpreted with some caution when estimating overweight or obesity clinical status among Singaporean adults. Clinicians and researchers should thus evaluate the potential and suitability of self-reports against their clinical or research requirements.

\section{Acknowledgement}

The study was funded by the Ministry of Health Singapore and Temasek Foundation Innovates.

\section{REFERENCES}

1. Deitel M. Overweight and obesity worldwide now estimated to involve 1.7 billion people. Obes Surg 2003;13:329-30.

2. Low S, Chin MC, Deurenberg-Yap M. Review on epidemic of obesity. Ann Acad Med Singap 2009;38:57-9.

3. Cheah JS. Obesity in Singapore. Ann Acad Med Singap 2001; 30:561-2.

4. Muralidhara DV. Body mass index and its adequacy in capturing body fat. Thai J Physiol Sci 2007;20:97-100. 
5. Low S, Chin MC, Ma S, et al. Rationale for redefining obesity in Asians. Ann Acad Med Singap 2009;38:66-9.

6. Chow PY, Lim FA, Wong SM, et al. Comparison of body mass index and subjective global assessment as indices of nutrition in hospital inpatients. Ann Acad Med Singap 2004;33(5 Suppl):S67.

7. Hall DM, Cole TJ. What use is the BMI? Arch Dis Child 2006; 91:283-6.

8. Connor Gorber SC, Tremblay M, Moher D, et al. A comparison of direct vs. self-report measures for assessing height, weight and body mass index: A systematic review. Obes Rev 2007;8:307-26.

9. Hayes AJ, Kortt MA, Clarke PM, et al. Estimating equations to correct self-reported height and weight: Implications for prevalence of overweight and obesity in Australia. Aust N Z J Public Health 2008;32:542-5.

10. Niedhammer I, Bugel I, Bonenfant S, et al. Validity of selfreported weight and height in the French GAZEL cohort. Int $\mathrm{J}$ Obes Relat Metab Disord 2000;24:1111-8.

11. Spencer EA, Appleby PN, Davey GK, et al. Validity of self-reported height and weight in 4808 EPIC-Oxford participants. Public Health Nutr 2002;5:561-5.

12. Wada K, Tamakoshi K, Tsunekawa T, et al. Validity of self-reported height and weight in a Japanese workplace population. Int $\mathrm{J}$ Obes (Lond) 2005;29:1093-9.

13. Lim LL, Seubsman SA, Sleigh A. Validity of self-reported weight, height, and body mass index among university students in Thailand: Implications for population studies of obesity in developing countries. Popul Health Metr 2009;7:15

14. Nyholm M, Gullberg B, Merlo J, et al. The validity of obesity based on self-reported weight and height: Implications for population studies. Obesity (Silver Spring) 2007;15:197-208.

15. Yong V, Saito Y. How accurate are self-reported height, weight, and BMI among community-dwelling elderly Japanese? Evidence from a national population-based study. Geriatr Gerontol Int 2012;12:247-56.

16. Nakamura K, Hoshino Y, Kodama K, et al. Reliability of selfreported body height and weight of adult Japanese women. J Biosoc Sci 1999;31:555-8.

17. Kee CC, Lim KH, Sumarni MG, et al. Validity of self-reported weight and height: A cross-sectional study among Malaysian adolescents. BMC Med Res Methodol 2017;17:85.

18. Wardle J, Haase AM, Steptoe A. Body image and weight control in young adults: International comparisons in university students from 22 countries. Int J Obes (Lond) 2006;30:644-51.

19. Paeratakul S, White MA, Williamson DA, et al. Sex, race ethnicity, socioeconomic status, and BMI in relation to selfperception of overweight. Obes Res 2002;10:345-50.

20. Gillum RF, Sempos CT. Ethnic variation in validity of classification of overweight and obesity using self-reported weight and height in American women and men: The Third National Health and Nutrition Examination Survey. Nutr J 2005;4:27.

21. Bostrom G, Diderichsen F. Socioeconomic differentials in misclassification of height, weight and body mass index based on questionnaire data. Int J Epidemiol 1997;26:860-6.

22. Yancey AK, Simon PA, McCarthy WJ, et al. Ethnic and sex variations in overweight self-perception: Relationship to sedentariness. Obesity (Silver Spring) 2006;14:980-8.
23. Peixoto Mdo R, Benicio MH, Jardim PC. Validity of self-reported weight and height: The Goiania study, Brazil [in Portuguese]. Rev Saude Publica 2006;40:1065-72.

24. Maukonen M, Mannisto S, Tolonen H. A comparison of measured versus self-reported anthropometrics for assessing obesity in adults: A literature review. Scand J Public Health 2018;46:565-79.

25. Subramaniam M, Abdin E, Vaingankar JA, et al. Tracking the mental health of a nation: Prevalence and correlates of mental disorders in the second Singapore mental health study. Epidemiol Psychiatr Sci 2020;29:e29.

26. Leys C, Ley C, Klein O, et al. Detecting outliers: Do not use standard deviation around the mean, use absolute deviation around the median. J Exp Soc Psychol 2013;49:764-6.

27. Cousineau D, Chartier S. Outliers detection and treatment: A review. Int J Psychol Res 2010;3:58-67.

28. Donoho DL, Huber PJ. The notion of breakdown point. In: Bickel PJ, Doksum KA, Hodges JL, Jr (Eds). A Festschrift for Erich L. Lehmann. Belmont, CA: Wadsworth; 1983:157-84.

29. McClelland GH. Nasty data: Unruly, ill-mannered observations can ruin your analysis. In: Reis HT, Judd CM (Eds). Handbook of Research Methods in Social and Personality Psychology. Cambridge: Cambridge University Press; 2000:393-411.

30. Shrout PE, Fleiss J. Intraclass correlations: Uses in assessing rater reliability. Psychol Bull 1979;86:420-8.

31. Jakobsson U, Westergren A. Statistical methods for assessing agreement for ordinal data. Scand J Caring Sci 2005;19:427-31.

32. Landis JR, Koch GG. The measurement of observer agreement for categorical data. Biometrics 1977;33:159-74.

33. Bland JM, Altman DG. Statistical methods for assessing agreement between two methods of clinical measurement. Lancet 1986; $327: 307-10$

34. Zaki R, Bulgiba A, Ismail R, et al. Statistical methods used to test for agreement of medical instruments measuring continuous variables in method comparison studies: A systematic review. PLoS One 2012;7:e37908

35. Zhou X, Dibley MJ, Cheng Y, et al. Validity of self-reported weight, height and resultant body mass index in Chinese adolescents and factors associated with errors in self-reports. BMC Public Health 2010;10:190

36. Koo TK, Li MY. A guideline of selecting and reporting intraclass correlation coefficients for reliability research. J Chiropr Med 2016; 15:155-63

37. Bolton-Smith C, Woodward M, Tunstall-Pedoe H, et al. Accuracy of the estimated prevalence of obesity from self reported height and weight in an adult Scottish population. J Epidemiol Community Health 2000;54:143-48.

38. Taylor AW, Grande ED, Gill TK, et al. How valid are self-reported height and weight? A comparison between CATI self-report and clinic measurements using a large cohort study. Aust N Z J Public Health 2006;30:238-46.

39. Brestoff JR, Perry IJ, Van den Broeck J. Challenging the role of social norms regarding body weight as an explanation for weight, height, and BMI misreporting biases: Development and application of a new approach to examining misreporting and misclassification bias in surveys. BMC Public Health 2011;11:331.

40. McHugh ML. Interrater reliability: The kappa statistic. Biochemia Med (Zagreb) 2012;22:276-82. 